Art. XXIV.-On some new species of Fossils from the Primordial or Potsdam group of Rensselaer county, N.Y. (Lower Potsdam); by S. W. FORD.

Archoocyathus? Rensselaericus, sp. nov.

THE only specimen clearly belonging to this species that has come under my notice is exceedingly small, being only 0.30 of by Mather and Emmons for the whole of the Lower Silurian of New York; but not by Vanuxem or Hall. Prof. Hall, in his works, has, like most others, employed the name Lower Silurian instead. As there is nothing in my view to be gained from restoring to the Lower Silurian the term Champlain, and no likelihood that it will ever be so restored, this term is here retained for a division of the Post-tertiary or Quaternary.

AM. Jour. Sci.-Third Series, Vol. V, No 27.-March, 1873. 
an inch in length, and having a diameter of not more than 0.16 of an inch at the larger extremity, when perfect. This specimen is, in appearance, a slender, delicately fluted cone, about

1.

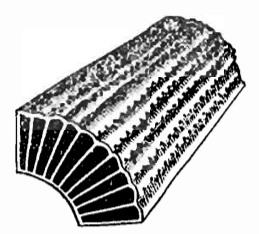

Fig. 1.-Portion of a specimen of A.? Rensselaericus, extending from the lation, greatly enlarged. one-third of which, including the apex, is imbedded in the rock. Of the remainder a considerable portion is in a badly damaged condition, the outer wall, with the greater part of its underlying septa, having been partially torn away. Such portion as remains uninjuren, however, is in an excellent state of preservation, and shows the leading features of structure in a very perfect manner. There remains, notwithstanding, much yet to be desired in order to completely characterize the species; and I have deferred any special notice of it hitherto in the hope of being able to obtain other, and possibly more perfect, specimens; but failing in this, I have thought it advisable to carry the description as far at this time as the material at hand will permit. The species may be described for the present as follows:

Elongate, conical, straight, gradually expanding from the base upward. Cup moderately large, depth unknown. Outer wall thick and strong, inner wall apparently much thinner. Radiating septa thin, numerous, not far from forty, judging from the number seen, sometimes a little irregular in their spacing. Dissepiments slender, occasionally absent, at other times dividing the interseptal spaces or loculi for a short distance into several compartments. Surface faintly annulated and longitudinally marked by numerous low, rounded ridges, with shallow intervening furrows, the ridges and furrows of about equal width. The ridges mark the position of the loculi, while the middle of each furrow indicates the place of one of the septa. Along each furrow and running its entire length are two straight rows of minute, closely arranged, circular pores opening into the loculi. The rows of pores of any given furrow are separated from each other by a thin strip or plate of the outer wall, corresponding in position and thickness to the septa; and it is a singular fact that the pores of either row are arranged alternately not only with respect to the other, but also with respect to those of the succeeding row in the next nearest furrow. The pores all communicate with the interior close to the septa where these latter join the outer wall; and as the rows of pores along any given furrow lead into distinct though adjacent loculi, it follows that all of the loculi were connected with the general surface by means of a double set of apertures. Whether the inner wall and radiating septa are perforate has not yet been made out. Color of the fossil, in gray limestone, when a little weathered, light brown. 
The above are the characters, so far as known, of this interesting and beautiful species, embracing only such as are displayed by the specimen mentioned at the beginning. These chiracters, taken together, are quite sufficient to distinguish it readily from any described species; while in respect to several of them, such as its straight form, longitudinally ribbed exterior, and remarkable poriferous system, the species appears to me at present sufficiently distinct from Archceocyathus to constitute a new though closely allied genus. Should a further study of it confirm this opinion, I propose to call it Archceocyathellus. Until, however, more can be said about it, I prefer to class it as above.

It is not improbable that the specimen upon which the description is based may be only the apical portion of a much larger and possibly curved specimen.

Occurs in conglomerate limestone of the Potsdam group at Troy; and also, doubtfully, in the condition of casts, in evenbedded limestone of the same locality. Collected by the writer.

\section{Obolella nitidla, sp. nov.}

Shell transversely sub-oval, small. Dorsal valve gently but irregularly convex, the greatest elevation occurring at a point about one-fifth the length of the valve from the apex. From this point the beak curves sharply down to the hinge-line which it almost touches. The hinge-line itself is slightly curved and apparently equal to about one-third the width of the shell. At the most elevated point of the valve commences a well-defined median depression, which extends forward for a distance of about one-half the length of the valve, gradually widening and becoming more shallow till it disappears. A portion of the dorsal valve close to the margin is sometimes nearly flat all around. The internal markings are not well enough shown in any of the specimens that I have seen to admit of description. The surface is ornamented with very fine concentric striæ and numerous close-set radiating striæ, the whole just visible to the unassisted eye.

The ventral valve is not certainly known. The width of the largest dorsal valve that I have seen is 0.14 of an inch and the length $0 \cdot 10$ of an inch.

Occurs in both even-bedded and conglomerate limestone of the Potsdam group at Troy. Collected by the writer.

Scenella retusa, sp. nov.

Shell small, rather strongly convex, aperture ovate, sides curved. Apex obtuse, nearly central, curving down a little toward one side. On the side toward which the apex is directed there are two faint grooves commencing near the tip of the apex and diverging to the margin. On the side opposite there is a well-marked carina running from the apex to the margin 
along the line of the longer axis of the shell. The slope of the shell is unequal, being most rapid toward the margin to which the apex inclines. The surface is marked by a few fine concentric and radiating lines, the latter only visible under a magnifier, and with obscure imbricating lines of grow th.

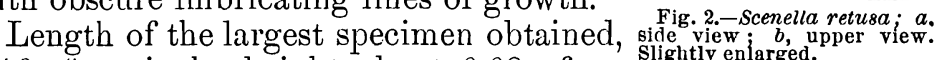
$0 \cdot 16$ of an inch; height about 0.08 of an inch. Occurs in both even-bedded and conglomerate limestone of the Potsdam group at Troy, associated with the preceding species. Collected by the writer.

This species is closely related to Scenella reliculata, the only hitherto published species of the genus, described by Mr. Billings in the Canadian Naturalist for July last from the Menevian group of Newfoundland. That species is, however, considerably larger than ours; and is, further, destitute of the diverging grooves which exist in $S$. retusa, and by which this latter species may be easily recognized.

\section{Hyolithes Emmonsi, sp. nov.}

Shell elongate, slender; apex neatly pointed, transverse section sub-triangular. Sides gently rounded and meeting to form a tolerably prominent though often scarcely perceptible dorsal ridge in the forward part of the shell, which quickly dies down, so that a transverse section taken near the apex would be almost a semi-circle. Ventral side flattened, with a wide, shallow depression along the middle, which runs the whole length of the shell; lateral edges rounded up to the sides. The most projecting

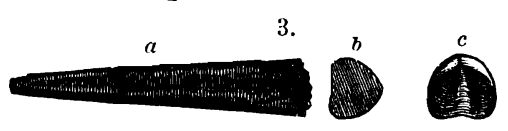

Fig. 3.-Hyolithes Emmonsi; a, ventral view of an imperfectly terminated specimen; $b$, transverse section; $c$, operculum, enlarged two diameters.

point of the lateral walls occurs close to the ventral side. When the width is 0.24 of an inch the depth is 0.18 of an inch. The walls of the shell are thick and appear to be made up in some instances of successive layers or laminæ. The surface is ornamented with very fine concentric striæ, which run directly around the shell or at right angles to its longitudinal axis. The tubes sometimes attain a length of two inches, even when imperfect; but the majority of the specimens in my possession are less than an inch in length.

The operculum has the same contour as a transverse section of the shell taken at about the mid-length, and is, accordingly, distinctly emarginate at the middle of the border of the ventral limb. The ventral limb itself is in the main flat, or nearly so, and embraces not far from two-thirds of the whole superfices of 
the operculum. Through the middle of it, beginning at the emargination, runs a low, rounded, conical elevation having the apex directed toward the dorsal limb and slightly encroaching upon it. The dorsal limb, unlike the ventral, is highly convex, except a narrow space near the margin, which is Gat. A narrow groove, extending from the apex of the cone just mentioned, or nucleus of the operculum, to the margin, occupies the central portion of this limb, and divides it into two equal parts. (A similar division is frequently well shown in the opercula of adult specimens of Hyolithes Americanus.) A portion of the operculum about the nucleus, of a triangular shape, is sometimes more elevated than the rest of the surface, and appears like a little plate added for strength. The surface is covered with fine, thread-like, concentric striæ.

In the slender form of the shell, the direction of the surface lines of the same, and the internal thickening already noticed, this species appronches closely the structure of a Salterella. Especially is this true when the specimens are quite small, as is usually the case; and in an earlier communication (this Journal for July, 1871), published prior to the discovery of specimens of its operculum, the species was referred hy me to that genus. It may be readily distinguished from either of the species of Hyolithes found with it by the direction of the surface lines of the shell and its distinctly hollowed ventral side.

Dedicated to the late Dr. Ebenezer Emmons, the eminent author of the "Taconic System."

This species occurs in both conglomerate and even-bedded limestone of the Potsdam group at Troy, associated wich $H$. Americanus, H. impar and Hyolithellus micans. It is not an abundant species, neither can it be considered as of rare occurrence. In a small specimen of the shell in my collection a transverse fracture shows a buckler of Agnostus? lobutus lying within the tube.

Dec. 3d, 1872. 